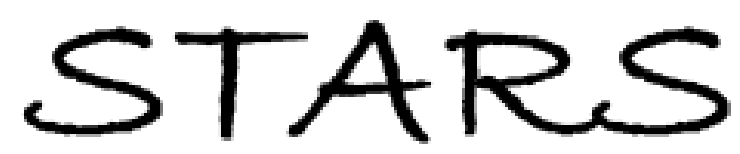

University of Central Florida

STARS

Faculty Bibliography 1990s

Faculty Bibliography

$1-1-1997$

\title{
Work function determination of zinc oxide films
}

K. B. Sundaram

University of Central Florida

Ashamin Khan

University of Central Florida

Find similar works at: https://stars.library.ucf.edu/facultybib1990

University of Central Florida Libraries http://library.ucf.edu

This Article is brought to you for free and open access by the Faculty Bibliography at STARS. It has been accepted for inclusion in Faculty Bibliography 1990s by an authorized administrator of STARS. For more information, please contactSTARS@ucf.edu.

\section{Recommended Citation}

Sundaram, K. B. and Khan, Ashamin, "Work function determination of zinc oxide films" (1997). Faculty Bibliography 1990s. 2110.

https://stars.library.ucf.edu/facultybib1990/2110

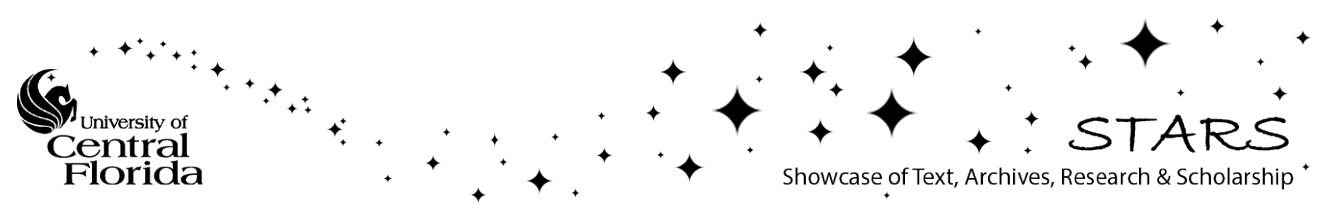




\section{Work function determination of zinc oxide films}

K. B. Sundaram, and Ashamin Khan

Citation: Journal of Vacuum Science \& Technology A 15, 428 (1997); doi: 10.1116/1.580502

View online: https://doi.org/10.1116/1.580502

View Table of Contents: https://avs.scitation.org/toc/jva/15/2

Published by the American Vacuum Society

\section{ARTICLES YOU MAY BE INTERESTED IN}

A comprehensive review of $\mathrm{ZnO}$ materials and devices

Journal of Applied Physics 98, 041301 (2005); https://doi.org/10.1063/1.1992666

Work function measurements on nano-crystalline zinc oxide surfaces

Journal of Applied Physics 111, 123710 (2012); https://doi.org/10.1063/1.4729527

ZnO Schottky barriers and Ohmic contacts

Journal of Applied Physics 109, 121301 (2011); https://doi.org/10.1063/1.3581173

Aluminum-doped zinc oxide films as transparent conductive electrode for organic light-emitting devices Applied Physics Letters 83, 1875 (2003); https://doi.org/10.1063/1.1605805

Work function of indium tin oxide transparent conductor measured by photoelectron spectroscopy

Applied Physics Letters 68, 2699 (1996); https://doi.org/10.1063/1.116313

On the optical band gap of zinc oxide

Journal of Applied Physics 83, 5447 (1998); https://doi.org/10.1063/1.367375

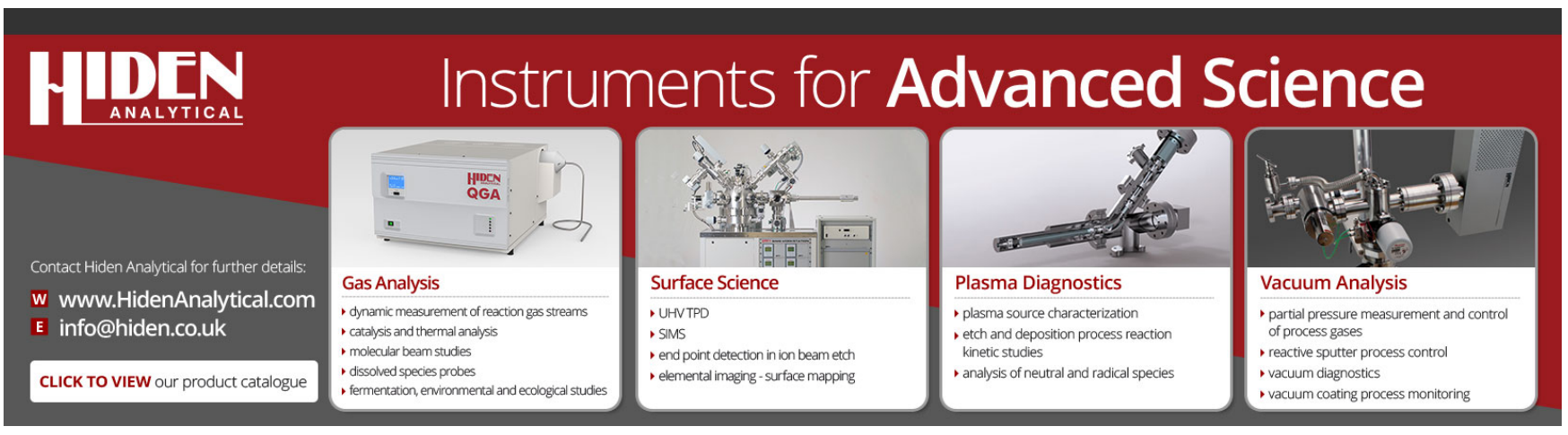




\title{
Work function determination of zinc oxide films
}

\author{
K. B. Sundaram ${ }^{\text {a) }}$ and Ashamin Khan ${ }^{\text {b) }}$ \\ Department of Electrical and Computer Engineering, University of Central Florida, Orlando, \\ Florida 32816-2450
}

(Received 28 May 1996; accepted 13 December 1996)

\begin{abstract}
Zinc oxide-silicon heterojunctions were fabricated using both $n$ - and $p$-type silicon. The zinc oxide films were deposited by the magnetron sputtering process at various substrate temperatures to form these devices. The electrical properties of these devices were measured and the work function of the zinc oxide was evaluated from these properties. (C) 1997 American Vacuum Society.
\end{abstract}

[S0734-2101(97)03102-3]

\section{INTRODUCTION}

Zinc oxide $(\mathrm{ZnO})$ is an $n$-type wide band-gap semiconductor that has potential application as a material for optoelectronic devices. Thin films of zinc oxide have been widely studied as a piezoelectric material for surface acoustic wave devices. ${ }^{1,2}$ Low-loss optical wave guides have been fabricated using epitaxial $\mathrm{ZnO}$ films. ${ }^{3}$ An electro-optic modulator was also reported using $\mathrm{ZnO}$ films. ${ }^{4} \mathrm{Zinc}$ oxide film has been used as a top contact window layer for solar cell applications due to its high optical transparency and electrically conducting nature..$^{5-7} \mathrm{ZnO}$ films have a high infrared reflectance and high visible transmittance. Presently indium tin oxide (ITO) layers are used as energy efficient windows for solar cells and liquid crystal displays. The components of ITO, namely, In and $\mathrm{Sn}$, are limited in supply and are more expensive than zinc. Further, for the fabrication of amorphous-silicon $(a-\mathrm{Si})$ solar cells, ITO coated glass substrates are used. The $a-\mathrm{Si}$ films are deposited onto the ITO layer by the plasma enhanced chemical vapor deposition (PECVD) process. During this deposition, ITO films are exposed to hydrogen plasma that reduces the metal oxide optical transparency. In and $\mathrm{Sn}$ based conducting layers are not wise to use for low cost solar cells. ZnO films are more stable than ITO based films in the presence of $\mathrm{H}_{2}$ plasma. In addition, zinc is a cheap, abundant, and nontoxic element. Although the optical and electrical properties of zinc oxide have been studied extensively, there is no report of the work function of zinc oxide films. In the present work, $\mathrm{ZnO}-\mathrm{Si}$ heterojunctions were fabricated and their electrical properties were measured. The work function of zinc oxide films was evaluated from these properties.

\section{EXPERIMENT}

Zinc oxide/silicon heterojunctions were prepared using both $n$ - and $p$-type wafers. All the samples were (100) silicon single-crystal wafers polished on one side only. The resistivities of the $p$-type samples were 10 and $23 \Omega \mathrm{cm}$ where as the resistivity of the $n$-type was $5 \Omega \mathrm{cm}$. The wafers were cut into pieces $1.5 \mathrm{~cm}$ long by $1 \mathrm{~cm}$ wide. The wafers were cleaned with boiling trichloroethane, acetone, and methanol

\footnotetext{
a)Electronic mail: kbs@ece.engr.ucf.edu

${ }^{b)}$ Present address: Sawtek Inc., Orlando, FL 32860-9501.
}

and then dipped in $1: 1 \mathrm{H}_{2} \mathrm{SO}_{4}: \mathrm{H}_{2} \mathrm{O}_{2}$ for $3 \mathrm{~min}$. Subsequently the wafers were etched with a buffered oxide etch (BOE) $\left(13 \mathrm{NH}_{4} \mathrm{~F}: 2 \mathrm{HF}\right)$ diluted with water for 3 min to remove any surface oxide. Finally the wafers were washed with deionized water and this was followed by blowing dry with nitrogen. To provide low resistance electrical contacts (ohmic contacts) to $p$-type $\mathrm{Si}$, a 300-nm-thick aluminum layer was deposited onto the back side of the wafer. For $n$-type $\mathrm{Si}$ a phosphorus doped nickel layer was deposited by the electroless plating method. ${ }^{8}$ The samples were annealed at $450{ }^{\circ} \mathrm{C}$ for $30 \mathrm{~min}$ for alloying in an argon ambient in order to get good ohmic contacts. Before deposition of the $\mathrm{ZnO}$ film, the front of the sample was etched in a BOE while masking the back side with Apiezon wax. The wax was removed with trichloroethylene and the wafers were cleaned and dried.

$\mathrm{ZnO}$ films were deposited in a radio frequency (rf) magnetron sputtering system (US Gun II) using a 5-cm-diam pressed zinc oxide target $(99.999 \%$ purity, Angstrom Sciences). The samples were placed into the system along with a metal shadow mask to form 1-2-mm-diam dots of $\mathrm{ZnO}$ onto the $\mathrm{Si}$. The target to substrate distance was $3.2 \mathrm{~cm}$. The system was evacuated to a pressure of $5 \times 10^{-6}$ Torr while the substrate was heated. The base pressure in the system was adjusted with a throttle valve to maintain it at $20 \times 10^{-3}$ Torr during deposition with an argon flow of $5 \mathrm{sccm}$. Before initiating the deposition onto the substrates, the target was precleaned for $15 \mathrm{~min}$. The $\mathrm{ZnO}$ films were deposited at different substrate temperatures ranging from 50 to $250^{\circ} \mathrm{C}$. The rf power used was $150 \mathrm{~W}$ and the films were deposited for $30 \mathrm{~min}$. Film thickness ranged from 250 to $300 \mathrm{~nm}$.

The $I-V$ characteristics of the fabricated diodes were measured using a Hewlett Packard semiconductor parameter analyzer (model HP4145B). All measurements were taken under dark conditions. Both the $I-V$ characteristics and the $\log I-V$ were plotted using the semiconductor parameter analyzer.

\section{RESULTS AND DISCUSSION}

The deposited zinc oxide films showed typical resistivity of nearly $10^{-2} \Omega \mathrm{cm}$. Both the $\mathrm{ZnO} / n-\mathrm{Si}$ and the $\mathrm{ZnO} / p-\mathrm{Si}$ junctions showed good rectifying characteristics. In the $\mathrm{ZnO} /$ $n$-Si junction, $\mathrm{Si}$ is negative for forward current, while the 


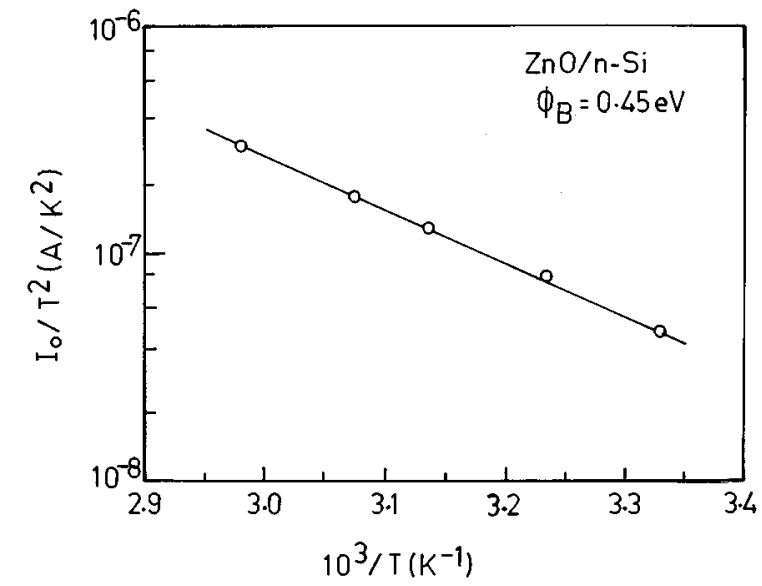

FIg. 1. Semi-log plot of $I_{0} / T^{2}$ vs $10^{3} / T$ for $\mathrm{ZnO} / n$-Si heterojunctions.

$\mathrm{ZnO} / p$-Si junction requires positive voltage on the $\mathrm{Si}$ for the forward bias condition. The forward biasing conditions are very similar to metal $/ n-\mathrm{Si}$ and metal $/ p-\mathrm{Si}$ Schottky barrier contacts. The room temperature reverse saturation current $\left(I_{0}\right)$ of the diodes was obtained by extrapolating the reverse current region of the $\log I-V$ plots. Because of the high conductivity of the $\mathrm{ZnO}$ films, it is assumed that the Fermi level coincides with the conduction band edge in the $\mathrm{ZnO}$. Under this assumption, the electron affinity and the work function of $\mathrm{ZnO}$ are nearly equal. The transition region is predominantly on the Si side for the junction. The discontinuity in the conduction band edge, $\Delta E_{c}$, is equal to the difference in the electron affinities between $\mathrm{ZnO}$ and $\mathrm{Si}$. In this context, the predominant current mechanism is assumed to be Schottky emission of carriers over the potential barrier for both $n$ - and $p$-type heterojunctions. The reverse saturation current density is of the form ${ }^{9}$

$$
J_{0}=I_{0} / A=A^{*} T^{2} \exp \left(-\phi_{B} / k T\right),
$$

where $I_{0}$ represents the reverse saturation current, $A$ is the junction area, $A^{*}$ is the Richardson constant, $\phi_{B}$ is the Schottky barrier height, $k$ is the Boltzman constant, and $T$ is temperature in kelvin. Semi-log plots of $I_{0} / T^{2}$ vs $10^{3} / T$ were plotted for devices with $n$ - and $p$-type substrates. $\phi_{B}$ was found from the slope of the line. Figure 1 shows the plot for $\mathrm{ZnO} / n$-Si heterojunctions from which $\phi_{B n}$ was found to be $0.45 \mathrm{eV}$. Figure 2 shows similar plots for $\mathrm{ZnO} / p$-Si junctions with $\mathrm{Si}$ resistivities of 10 and $23 \Omega \mathrm{cm}$, respectively. Here, $\phi_{B p}$ values were found to be 0.72 and $0.69 \mathrm{eV}$, respectively, for the above samples of Fig. 2. Based on the simple Schottky-Mott model, the work function $\Phi_{m}$ of $\mathrm{ZnO}$ was calculated using the relation of $\Phi_{m}=X_{\mathrm{Si}}+\phi_{B n}$, for the junction with $n$-Si and $\Phi_{m}=E_{g}+X_{\mathrm{Si}}-\phi_{B p}$ for $p$-Si, where $X_{\mathrm{Si}}$ and $E_{g}$ are the electron affinity and band gap of silicon having values of 4.05 and $1.12 \mathrm{eV}$, respectively. ${ }^{9}$ The work function values for $\mathrm{ZnO}$ ranged from 4.45 to 4.5 for the fabricated devices. This work function value is close to the value reported for the defect free $\mathrm{ZnO}$ (1010) single crystals by Göpel et al., ${ }^{10}$ Further, $\phi_{B n}+\phi_{B p}$ gives a value of 1.155 $\mathrm{eV}$ that is very close to the band gap of $\mathrm{Si}$.

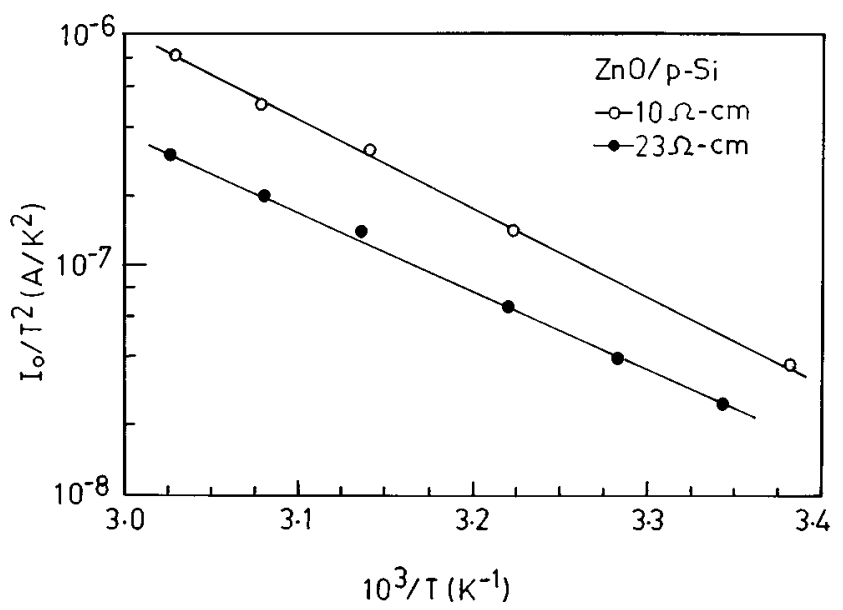

FIG. 2. Semi-log plot of $I_{0} / T^{2}$ vs $10^{3} / T$ for $\mathrm{ZnO} / p$-Si heterojunctions.

Prior to $\mathrm{ZnO}$ deposition, the Si surface was chemically cleaned and this process invariably leaves a thin (1-2 nm) insulating oxide layer on the semiconductor surface. Because of the presence of an insulating layer between $\mathrm{Si}$ and $\mathrm{ZnO}$, according to the Bardeen model the barrier heights $\phi_{B n}$ and $\phi_{B p}$ are modified approximately and are given by ${ }^{9}$

$$
\phi_{B n}=C\left(\Phi_{m}-X_{\mathrm{Si}}\right)+(1-C)\left(E_{g}-\phi_{0}\right),
$$

where

$$
C=\frac{\epsilon_{i}}{\epsilon_{i}+q^{2} \delta D_{s}},
$$

where $\delta$ the thickness of the oxide layer, and $\epsilon_{i}$ its total permittivity. The surface states are assumed to be distributed in energy within the band gap, with density of states $D_{s} / \mathrm{cm}^{2}$. The position of neutral level $\phi_{0}$ is measured from the top of the valence band. A similar analysis for the case of a $p$-type semiconductor shows that $\phi_{B p}$ is approximately given by

$$
\phi_{B p}=C\left(E_{g}-\Phi_{m}+X_{\mathrm{Si}}\right)+(1-C) \phi_{0} .
$$

For a given interfacial layer thickness, $\left(\phi_{B n}+\phi_{B p}\right) \approx E_{g}$, owing to the similarity of the surface states in $p$ - and $n$-type Si.

Using the data from the previous work by Turner and Rhoderick for their metal $/ n$-Si Schottky barriers ${ }^{11}$ with $q D_{s}=2 \times 10^{12} / \mathrm{cm}^{2}$ for $n-\mathrm{Si}, \delta=1.5 \mathrm{~nm}$, and $\epsilon_{i}=3.9, \phi_{0}=0.27$ $\mathrm{eV}$, and assuming the work function of $\mathrm{ZnO}$ to be around 4.5 $\mathrm{eV}$ as calculated above in our experiment, $\phi_{B n}$ was calculated using Eq. (2) and was found to be $0.49 \mathrm{eV}$. The range of $\delta$ taken corresponds to the range over which the model can be reasonably expected to hold, i.e., tunneling can take place through the interfacial layer, the parasitic resistance of which can be taken as zero. Similarly, using the data from previous work by Smith and Rhoderick ${ }^{12}$ with $q D_{s}=3 \times 10^{12} / \mathrm{cm}^{2}$ for $p-\mathrm{Si}$, and $\phi_{0}=0.33 \mathrm{eV}, \phi_{B p}$ was calculated using Eq. (3) and was found to have a value of 0.61 $\mathrm{eV}$. Therefore, assuming the presence of an insulating layer between $\mathrm{ZnO}$ and $\mathrm{Si}, \phi_{B n}$ increased and $\phi_{B p}$ decreased compared with the conventional Schottky-Mott model approach. Deposition of $\mathrm{ZnO}$ at higher temperatures will cause growth 


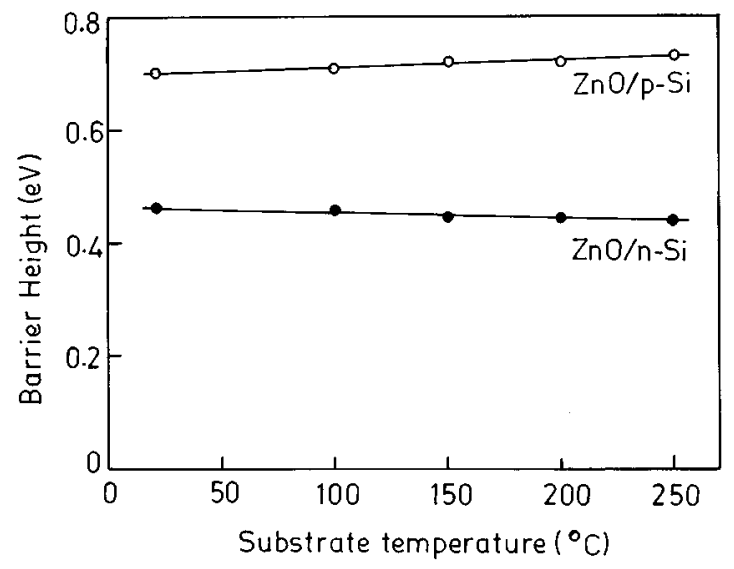

FIG. 3. Barrier height as a function of substrate deposition temperature.

of the oxide and a subsequent reduction in the density of states. Based on Eqs. (2) and (3), this reduction in the density of states will cause a decrease in $\phi_{B n}$ for the $n$-Si device and an increase in $\phi_{B p}$ for $p$-Si. A similar trend was observed with only small changes in the barrier heights for both $\mathrm{ZnO} /$ $n$-Si and $\mathrm{ZnO} / p$-Si junctions prepared by depositing $\mathrm{ZnO}$ at higher substrate temperatures and is shown in Fig. 3. Again, $\phi_{B n}+\phi_{B p}$ corresponds approximately to $E_{g}$ of Si. Deposition at higher temperature will increase oxygen diffusion towards the $\mathrm{Si}$ interface and this will make $\mathrm{ZnO}$ less stoichiometric due to a greater oxygen deficiency. More oxygen defects in $\mathrm{ZnO}$ will correspond to a reduced work function of
$\mathrm{ZnO}$. This work function reduction will decrease $\phi_{B n}$ and increase $\phi_{B p}$ based on the above equations. The same trend is seen in Fig. 3. A similar reduction in work function was observed by Göpel et al. when the $\mathrm{ZnO}$ single crystal had more defects. ${ }^{10}$

\section{CONCLUSIONS}

The work function of sputter deposited $\mathrm{ZnO}$ films was obtained from the electrical properties of $\mathrm{ZnO} / p-\mathrm{Si}$ and $\mathrm{ZnO} /$ $n$-Si junctions. The estimated values of the work function based on the Schottky barrier model showed values between 4.45 and $4.50 \mathrm{eV}$ for the films. These values were also interpreted by assuming the presence of a very thin $\mathrm{SiO}_{2}$ layer at the interface of $\mathrm{ZnO}$ and $\mathrm{Si}$.

${ }^{1}$ F. S. Hickernell, IEEE Trans. Sonics Ultrason. 32, 621 (1986).

${ }^{2}$ S. Maniv and A. Zangvil, J. Appl. Phys. 52, 2787 (1978).

${ }^{3}$ M. Wu, A. Azuma, T. Shiosaki, and A. Kawabata, J. Appl. Phys. 62, 2482 (1987).

${ }^{4}$ D. Persegol, E. Pic, and J. Plantier, J. Appl. Phys. 62, 2563 (1987).

${ }^{5}$ N. G. Dhere, Thin Solid Films 193-194, 757 (1990).

${ }^{6}$ J. Aranovich, A. Ortiz, and R. H. Bube, J. Vac. Sci. Technol. 16, 994 (1979).

${ }^{7}$ J. Hu and R. G. Gordon, J. Electrochem. Soc. 139, 2014 (1992).

${ }^{8}$ M. V. Sullivan and J. H. Eigler, J. Electrochem. Soc. 104, 226 (1957).

${ }^{9}$ S. M. Sze, Physics of Semiconductor Devices, 2nd ed. (Wiley, New York, 1981), pp. 256 and 270

${ }^{10}$ W. Göpel, L. J. Brillson, and C. F. Brucker, J. Vac. Sci. Technol. 17, 894 (1980).

${ }^{11}$ M. J. Turner and E. H. Rhoderick, Solid-State Electron. 11, 291 (1968).

${ }^{12}$ B. L. Smith and E. H. Rhoderick, Solid-State Electron. 14, 71 (1971). 